\title{
Resistivity Comparison of Concretes Receptacle of Yam to Produce Concrete Sheets with a High Resistance
}

\author{
Moein Zargar ${ }^{1}$, Hossein Gholami ${ }^{2}$, Hossein Norouzi ${ }^{3}$, Morteza Soltani ${ }^{4}$, Majedeh Haeri- \\ Hamedani $^{5}$, Vijay P. Singh ${ }^{6}$, Mohsen Ghane $^{7^{*}}$, Kaveh Ostad-Ali-Askari $^{2}$ \\ ${ }^{I}$ Department of Civil Engineering, Farzanegan Institute of Higher Education, Isfahan, Iran. \\ $2^{*}$ Department of Civil Engineering, Isfahan (Khorasgan) Branch, Islamic Azad University, Isfahan, Iran. \\ ${ }^{3}$ Department of Civil Engineering, Maybod Branch, Islamic Azad University, Maybod, Yazd, Iran. \\ ${ }^{4}$ Department of Architectural Engineering, Shahinshahr Branch, Islamic Azad University, Shahinshahr, Iran \\ ${ }^{5}$ Department of Biological and Agricultural Engineering \& Zachry Department of Civil Engineering, Texas A \\ and M University, 321 Scoates Hall, 2117 TAMU, College Station, Texas 77843-2117, U.S.A. \\ ${ }^{6}$ Civil Engineering Department, South Tehran Branch, Islamic Azad University, Tehran, Iran \\ ${ }^{7}$ Civil Engineering Department, South Tehran Branch, Islamic Azad University, Tehran, Iran
}

\author{
*Corresponding Author: Mohsen Ghane, Civil Engineering Department, South Tehran Branch, Islamic \\ Azad University, Tehran, Iran
}

\begin{abstract}
Nowadays all know the importance of seismic resisting of buildings in earthquake-prone areas. With regard to this point that present concrete buildings are generally designed and built based on ancient regulations without considering the effect of earthquake forces and the new regulations don't estimate any tremble, so, these buildings must be resistance able. We can use different methods to repair destructed concrete buildings by the earthquake or to accomplish tremble resistance of present concrete buildings. There are two ways of using steel sheets and FRP sheets for concrete members reinforcement or restoration. Each of these two methods is unstandardization of these materials with concrete and lack of coordination in their manner and characteristics. In this article, we try to compare concretes which one consist of above yam frame the point of view of compressive and tonsorial resistance to produce concrete sheets with high resistance completely, that at last simple's receptacle of steel sheets had better results of compressive and tonsorial resistance to produce these sheets into other samples.
\end{abstract}

Keywords: Strengthening; concrete sheet; steel yam; glass yam; Agamid yam.

\section{INTRODUCTION}

Considerable empirical work was performed to check the mechanical stability of fiber-reinforced weightless covered concrete.Although frame the beginning of creating concrete, there is a little evolution in its structure, but a vast spectrum of concrete usage actually shows us that a lot of material (cheap, accessible, resistant, ...) overshadows its other points. In the last few decades, to create homogeneous conditions and reduce concrete frangibility weakness some deal, they use frangible and long fibres that scatter in all of the concrete mass homogeneously and interfused.

\section{REINFORCED CONCRETE TO STEEL YAM}

In recent years there has been made vast researches and they tried to recover concrete characteristics by adding steel yam. At present time, reinforced concrete with steel yam is considered as one of the new building materials, differ and with some specifications that are unique from the point of view of resistance, tensorial ability and bearing against rupture. Main materials of reinforced concrete with yam are like usual concretes (Aram M, Zomorodian S.M.A., Vakili A.H, Vakili A. 2008). Apply of Yam Steel materials for fortifying and maintenance of structural members has become a progressively popular zone of investigation and application in the last decade. However, the procedure is yet to become a normal usage owing to a number of financial and plan related matters. From a structural technicians standpoint, significant concern about the success and security of this procedure is the 
possible of brittle debonding failures. Such collapse, unless often examined in the design process, may notably reduce the benefit of the fortifying or mend application. In new years, there has been an attentiveness of research attempts on the characterization and modeling of yam steel. This article prepares a revision of the improvement achieved in this zone about applications to steel yam. The noticable fragility with low tensile strength and strain capacities of high-strength concrete can get over by the surplus of steel yam. This article considered the mechanical attributes of high-strength steel yam. Stability models were appointed to forecast the compressive and splitting tensile stabilities and modulus of disconnection of the fiber-reinforced concrete. This investigation examines the optimization of steel yam regard on general mechanical features. The various sizes are of steel yam donated to various mechanical features, at least to a various degree. The fracture features and the dynamic features will be examined for the fibers concrete with well general mechanical features of steel yam. steel yam is progressively being applied day by day as a structural material. The result of steel yam addition to concrete on some of the major parameters namely peak stress, strain at peak stress, the hardness of concrete and the nature of the stress-strain curve is examined. There happens a good correlation between the experiential consequences and those computed depend on the logical model. Equations are also suggested to measure the result of steel yam on compressive strength, strain at peak stress and the hardness of concrete in terms of steel yam parameter.

Materials that have a high quality are usable in yam concrete and hardened concrete specifications are accessory of concrete placing methods and compression of concrete paste. Yam concrete is a mixture that consists of a concrete mould which is composed of cement, stone materials, water and a percent of short yam that are spread in mixture occasionally and unsettled in different sides that improves the presence of concrete specifications steel yam to a special state. In this survey, armature networks, waved nets or long and thin armatures can't be considered as unique and outspread yam (Aram M, Zomorodian S.M.A., Vakili A.H, Vakili A. 2008.). The influence of yam concrete on preventing crack propagation in concrete was examined. The concrete yam structure shows improved stability, flexibility and fire resistance. A major sign of this kind of structure is the bond relationship introduced between steel and concrete, which straightly increases the load capacity of the structure. The issue of steel corrosion in concrete structures in the intense environment has been an absorbing aspect in fields of erosion and civil engineering materials which it improves with steel yam. The mechanism of erosion in concrete induced by the steel depassivation is still obscure so far that steel yam has a significant role in improving it. Moreover, steel yam is affected by many factors, which finally dues to the strength of reinforced concrete structures and the increase of service life. This article is concerned with an experiential study on the final load behavior of steel yam in the plan. The experiential consequences for deformations steel yam, for stress dispensations and for final stabilities were found to be in nice agreement with the corresponding values can predict by finite element analysis. Steel yam is applied extensively in modern buildings. vast investigation on steel yam in which structural steel section is encased in concrete has been carried out. it can consider steel yam is given with importance on experiential and scientific work.

\subsection{Yam Concrete Advantages}

Usual concrete is a material that is partly brickle and frangible. While yam concrete can prevent fraction because of high resistance, so is better than a usual concrete (Aram M, Zomorodian S.M.A., Vakili A.H, Vakili A. 2008). The treatment of composite steel-concrete yam at high temperatures is an important issue. steel yam elements are being examined global as a complete kind of reinforcement for concrete structures. It can use a finite element program for the nonlinear analysis of steel-concrete yam. The program can examine the nonlinear behavior of concrete, steel yam. it sometimes uses some samples of structural systems that use steel yam in bridge structures and composite rebars as reinforcement to concrete. Steel yam may be applied when environmental adverse situations corrode the steel in reinforced concrete. The high specific strength of steel-concrete yam is essential when examining the supporting cables of suspension bridges. This article examines innovative connections which allow steel and concrete yam structures to be made complete.

\subsection{Aramid Yam}

Aramid yam that is introduced about 1970, are annular organic admixing of carbon, hydrogen, oxygen and nitrogen. Low density and high tensorial consistency in these yams cause to constitute a residual 
structure to the impact with a duress about half of the carbon yam. Aramid yam at first is made to replace steel in radial tires and then have found another usage.one of the most successful Aramid yam usage is butte proof jacket.Aramid exists in two structures of straight bond named to collar and cure bond named to Nomex (Aram M, Zomorodian S.M.A., Vakili A.H, Vakili A. 2008).

The 'Aramid yam has a circular cross-section, are birefringent and resistant at temperatures. But significant tries to enhance aramid-epoxy adhesion, the adhesion levels got between aramid yam and epoxy matrices are less than best for some usages. Composition of the aramid yam physical and chemical features and the interfacial mechanical stresses are in charge of the shortage of success in enhancing aramid-epoxy adhesion level. A clue to bettering the aramid-epoxy sticking is a basic comprehension of the interfacial mechanisms by which fiber and matrix cooperate. There is a significant number of propagations on aramid yam and their composites. This article examines some of the literature linked to aramid yam bonding mechanisms. The interrelation between shape and mechanical features for a series of well-characterized aramid yam has been defined. The aramid yam was created under a diversity of processing situations. It has been an exhibit that the mechanical features of the aramid yam are qualified by the aramid yam structure.

\subsection{Glass Yam}

Glass yam is the most famous invigorator that is used in composite industry and there are different commercial kinds of it that some of them are as follows: AR, ECR, C, S, E.

Chemical compounds of these yam are different and each one is suitable for a special usage. Approximately 90 percent of usable yam in engineering composites is glass yam. Glass yam has a suitable hardness, hold its mechanical properties in high temperatures, has a suitable moisture and erosion resistance and is nearly cheap (Aram M, Zomorodian S.M.A., Vakili A.H, Vakili A. 2008).

\section{RESUlts RELATED TO THE COMPRESSIVE SAMPLES}

Figure 2 shows made samples. As its distinguished in picture. Samples are broken conical that is the most ideal kind of concrete break. After making some samples without yam, in the next step, its steel, glass and Aramid yam samples. This concrete grout, as we explained before will be produced, moreover at last we add yam to grout. Figure 1 shows a bulk of steel yam. Applying steel yam is began from the middle of the last century. Primary substances of reinforced concrete with yam are similar to normal concretes. Steel yam samples mix with grout harder than glass and Aramid. (Aram M, Zomorodian S.M.A., Vakili A.H, Vakili A. 2008).

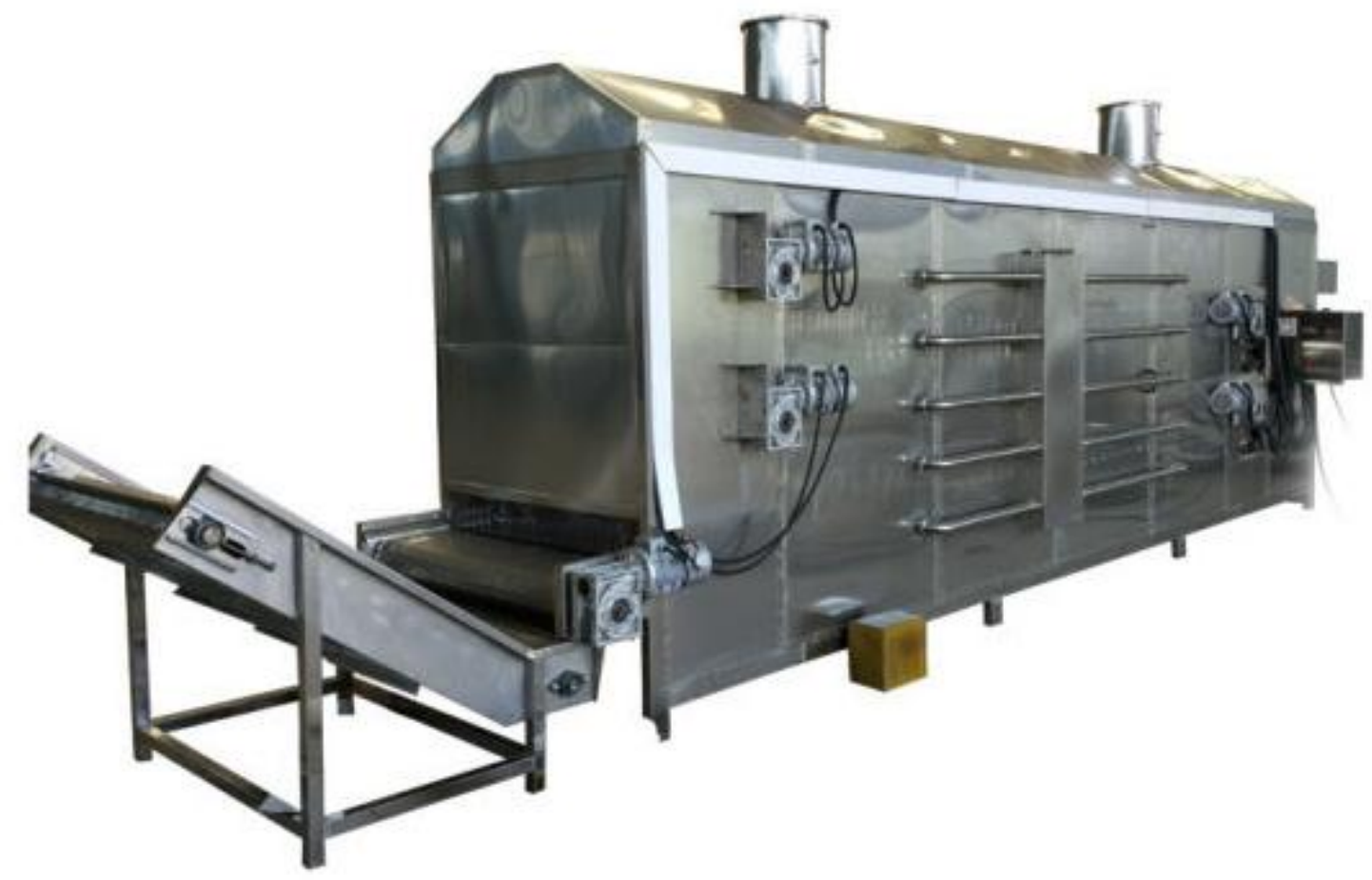

Figure1. A bulk of steel yam. 


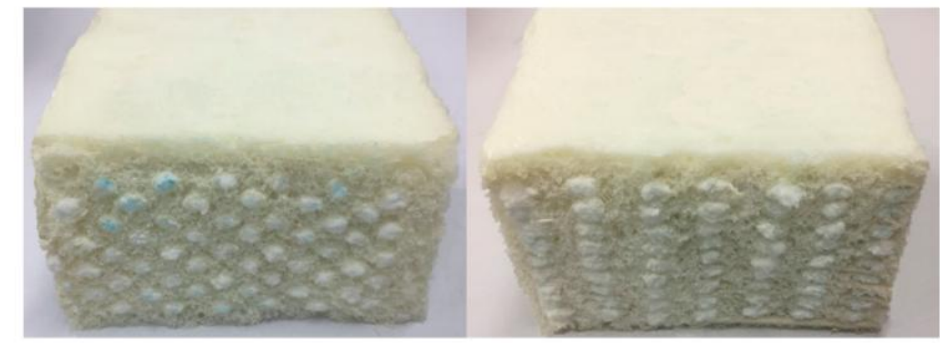

(a)

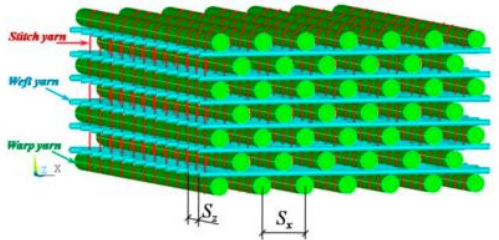

(c) (b)

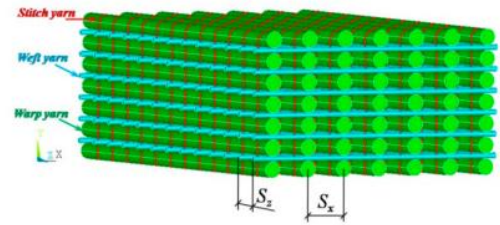

(d)

Figure2. Broken samples without yam.

\subsection{Results}

High strength, corrosion resistance and electromagnetic neutrality make Fiber Reinforced Plastics (FRP) appropriate candidates in many submissions, with consolidation and the expansion of novel members. While the use of composite materials has enlarged meaningfully over the years, its submission to civil engineering structures has been curbed. This study inspects the applicability of the fiber as a consolidation material for structural concrete members through numerous investigational efforts for strength, mechanical belongings and flexural strengthening. These days all recognize the significance of earthquake withstanding of constructions in earthquake-prone zones. With regard to this point that available concrete constructions are commonly invented and constructed depend on ancient regulations without considering the effect of earthquake forces and the new regulations don't appraise any quake, so, these constructions must be persistence able. Investigation on standard of HPFRCC material as one of the most appropriate local persistence procedures of the concrete constructions member has considerate impotence. A systematic model for the maximum accessible prestress expanded in an earlier study is tabloid and confirmed with experiments; a significant settlement between notion and experience was found. Additional studies, both logical and investigational, on the flexural behavior of concrete beams reinforced with prestressed FRP sheets prove the greater presentation of the hybrid organization and stress its favorable strength, difficulty and ductility features.

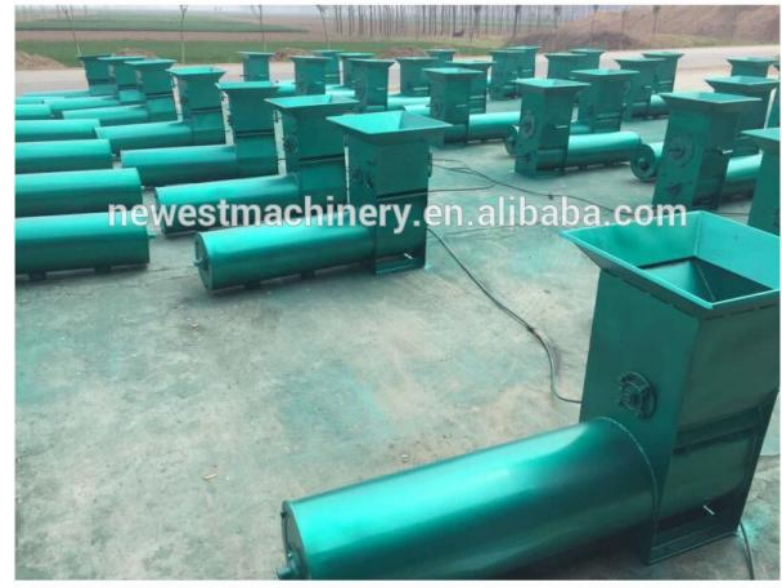

Figure3. Broken samples with steel yam.

\section{CONClusion}

Scholars have displayed that the recent HPFRCC substance that mostly is a concrete with a great persistence with steel, glass, aramid and carbon yam has appropriate performance proportion with concrete and can enhance concrete persistence frame the viewpoint of curving and regional as these 
two other substances. In this study, we attempt to contrast concretes which one consist of above yam frame the viewpoint of pressing and tonsorial persistence to generate concrete sheets with high persistence entirely, that at last simple's holder of steel sheets had better consequences of pressing and tonsorial persistence to generate these sheets into other specimens.

As it is distinguishable in Fig. 4, samples without yam are broken from middle part because tensorial resistance in somewhere that has least mass is low. But in Fig. 5, samples that have yam are broken

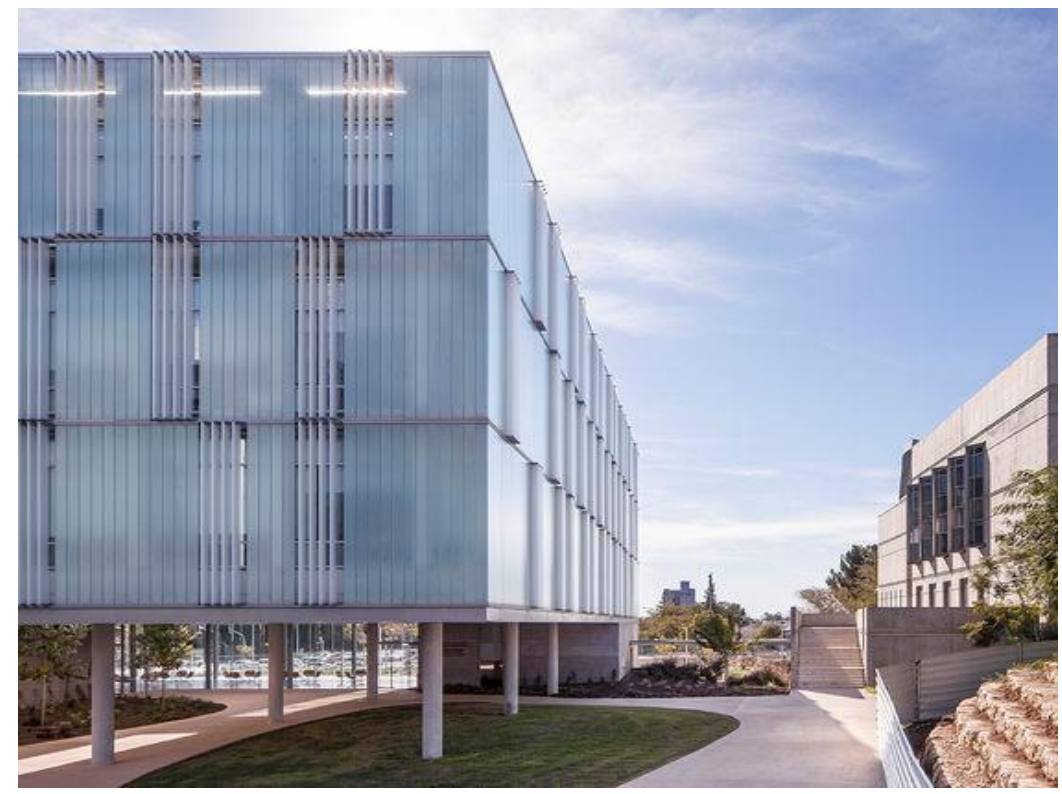

Fig4. Sample with glass yam

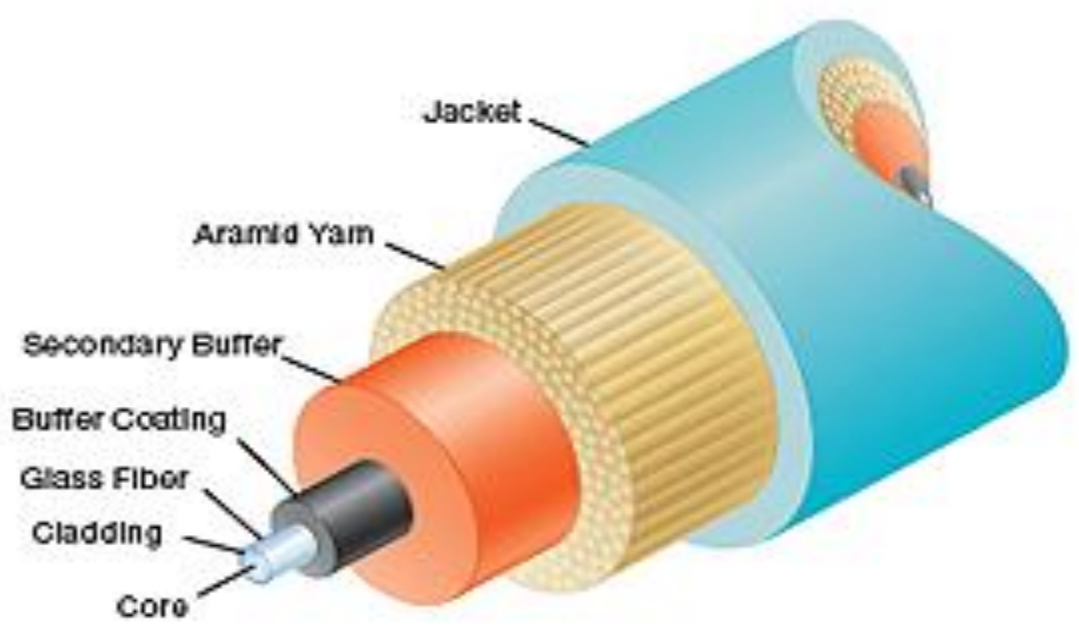

Fig5. Broken sample of Armaid yam

from he places of jack that probably it is because of tension in that place.

\section{ACKNOWLEDGMENT}

This research was supported by the Isfahan University of the Technology. We thank our all authors who provided insight and expertise that greatly assisted the research.

\section{AUTHOR'S CONTRIBUTIONS}

All authors contributed to design the study, write and revise the manuscript.

\section{ETHICS}

The present Study and ethical aspect were approved by the Isfahan University of the Technology. The present study was approved by the Isfahan University of Technology. 


\section{REFERENCES}

[1] Whan Han,Jin Wook Kang, Chang Seok Lee. 2018. Cyclic behavior of diagonally reinforced slender HPFRCC coupling beams with reduced diagonal and transverse reinforcement. Composite Structures, Volume 206, 15 December 2018, Pages 550-562.

[2] Haekook Jung, Sangin Park, Seungwon Kim, Chelwoo Park. 2017. Performance of SIFCON based HPFRCC under Field Blast Load. Procedia Engineering, Volume 210, 2017, Pages 401-408.

[3] Doo-Yeol Yoo, Jung-Jun Park, Sung-Wook Kim. 2017. Fiber pullout behavior of HPFRCC: Effects of matrix strength and fiber type. Composite Structures,Volume 174, 15 August 2017, Pages 263-276.

[4] M. Mansur Tufekci, Ahmet Gokce. 2017.Development of heavyweight high performance fiber reinforced cementitious composites (HPFRCC) - Part I: Mechanical properties.Construction and Building Materials, Volume 148, 1 September 2017, Pages 559-570.

[5] Doo-Yeol Yoo, Min-Jae Kim, Soonho Kim, Gum-Sung Ryu, Kyung-Taek Koh. 2018. Effects of mix proportion and curing condition on shrinkage behavior of HPFRCCs with silica fume and blast furnace slag. Construction and Building Materials, Volume 166, 30 March 2018, Pages 241-256

[6] Ali Hemmati, Ali Kheyroddin, Mohammad Sharbatdar, Yeonho Park, Ali Abolmaali. 2016. Ductile behavior of high performance fiber reinforced cementitious composite (HPFRCC) frames. Construction and Building Materials, Volume 115, 15 July 2016, Pages 681-689.

[7] Koichi Kobayashi, Keitetsu Rokugo. 2013. Mechanical performance of corroded RC member repaired by HPFRCC patching. Construction and Building Materials, Volume 39, February 2013, Pages 139-147.

[8] M. Mansur Tufekci, Ahmet Gokce. 2018. Development of heavyweight high performance fiber reinforced cementitious composites (HPFRCC) - Part II: X-ray and gamma radiation shielding properties. Construction and Building Materials, Volume 163, 28 February 2018, Pages 326-336.

[9] Alessandro P. FANTILLI, Hirozo MIHASHI, Paolo VALLINI, Bernardino CHIAIA. 2009. THE DUCTILE BEHAVIOR OF HPFRCC IN COMPRESSION. Brittle Matrix Composites 9, 2009, Pages 121-130.

[10] Won-Chang Choi, Hyun-Do Yun, Chang-Geun Cho, Luciano Feo. 2014. Attempts to apply high performance fiber-reinforced cement composite (HPFRCC) to infrastructures in South Korea. Composite Structures, Volume 109, March 2014, Pages 211-223.

[11] Enrique del Rey Castillo, Michael Griffith, Jason Ingham. 2018. Seismic behavior of RC columns flexurally strengthened with FRP sheets and FRP anchors. Composite Structures, Volume 203, 1 November 2018, Pages 382-395.

[12] Davood Mostofinejad, Mohammadjavad Hajrasouliha. 2019. 3D beam-column corner joints retrofitted with X-shaped FRP sheets attached via the EBROG technique. Engineering Structures, Volume 183, 15 March 2019, Pages 987-998.

[13] Nassereddine Attari, Youcef Si Youcef, Sofiane Amziane. 2019. Seismic performance of reinforced concrete beam-column joint strengthening by frp sheets. Structures, Volume 20, August 2019, Pages 353-364

[14] Armin Jafari, Asghar Vatani Oskouei, Milad Bazli, Rasool Ghahri. 2018. Effect of the FRP sheet's arrays and NSM FRP bars on in-plane behavior of URM walls. Journal of Building Engineering, Volume 20, November 2018, Pages 679-695.

[15]Evgenia Anagnostou, Theodoros C. Rousakis, Athanasios I. Karabinis. 2019. Seismic retrofitting of damaged RC columns with lap-spliced bars using FRP sheets. Composites Part B: Engineering, Volume 166, 1 June 2019,Pages 598-612.

[16] Theodoros C. Rousakis, Georgios D. Panagiotakis, Emmanouela E. Archontaki, Alexandros K. Kostopoulos.2019. Prismatic RC columns externally confined with FRP sheets and pre-tensioned basalt fiber ropes under cyclic axial load. Composites Part B: Engineering, Volume 163, 15 April 2019, Pages 96-106.

[17] M. Schulte, S. Steentjes, N. Leuning, W. Bleck, K. Hameyer.2019. Effect of manganese in high silicon alloyed non-oriented electrical steel sheets. Journal of Magnetism and Magnetic Materials, Volume 477, 1 May 2019, Pages 372-381.

[18] Ken-ichiro Mori, Yohei Abe, Kyohei Sedoguchi. 2019. Delayed fracture in cold blanking of ultra-high strength steel sheets. CIRP Annals, In press, corrected proof, Available online 1 May 2019.

[19] J. H. Choi, S. L. Zang, M. G. Lee, J. H. Kim, F. Barlat. 2019. Determining the coefficients of a homogeneous anisotropic hardening model for ultrathin steel sheets. International Journal of Mechanical Sciences, Volumes 157-158, July 2019, Pages 428-438.

[20]Lijun Xiao, Guodong Yu, Jibin Zou, Yongxiang Xu, Weiyan Liang. 2019. Experimental analysis of magnetic properties of electrical steel sheets under temperature and pressure coupling environment. Journal of Magnetism and Magnetic Materials, Volume 475, 1 April 2019, Pages 282-289. 
[21] Kaushik Bandyopadhyay, Shamik Basak, et al. 2019. Improved formability prediction by modeling evolution of anisotropy of steel sheets. International Journal of Solids and Structures, Volumes 156157, January 2019, Pages 263-280.

[22] Boxin Wang, Henan Jin, Teng Man, Qing Wang. 2016. Study on the mechanical property of textile reinforced self-stressing concrete sheets. Construction and Building Materials, Volume 107, 15 March 2016, Pages 1-10.

[23] Cheng Yuan, Wensu Chen, Thong M. Pham, Hong Hao. 2019. Bond behaviour between hybrid fiber reinforced polymer sheets and concrete. Construction and Building Materials, Volume 210, 20 June 2019, Pages 93-110.

[24] Akbar Hajipour Prof Mahmod Reza Mahery Mehrad Aram, 2008. Producing High Strength Concrete Plates Reinforced To Steel Fibers To Protect Reinforced Concrete Construction.Scientific, Research And Information Science Quarterrly Peridical Of Crisis And Reform Management International Civil\& Retofitting, Wintter.

[25]Burak Felekog־Lu*, Selc,Uk Tu Rkel, 2007. Yig It Altuntas, Effects Of Steel Fiber Reinforcement On Surface Wear Resistance Of Self-Compacting Repair Mortars, Department of Civil Engineering, Dokuz Eylu“ L University, 35160 Izmir, Turkey 2007

[26] Osman U* Nala, Fuat Demirb, Tayfun Uygunog־ Lua, 2006. Fuzzy Logic Approach To Predict StressStrain Curves Of Fiber-Reinforced Concretes In Compression, Building And Environment, October.

[27] Concrete Technology, A.M. Neville \& J.J. Brooks.

[28] Pullout Behaviour of Fibers in Steel Fiber Reinforced Concrete, Bernd Weiler, Christian Grosse 2008.

[29]Ductile Double-Lap Joints from Brittle Gfrp Laminates And Ductile Adhesives, Part Ii: Numerical Investigation And Joint Strength Prediction, Julia De Castro, Thomas Keller, Composites: Part B 39 (2008) 282-291.

[30] The Static Behavior Of A Modular Foam-Filled Afrp Bridge Deck With A Strong Web-Flange Joint Goangseup Zi, Byeong Min Kim, Yoon Koog Hwang, Young Ho Lee C, Composite Structures 85 (2008) $155-163$

[31] Aram M, Zomorodian S.M.A., Vakili A.H, Vakili A. 2008.Comparison of strength between fiber-reinforced concrete for the production of high strength concrete sheets. First International Conference on Seismic Rehabilitation, Tabriz, Iran, Oct. 29 to Nov. 2008.

[32] Devid Falliano, Dario De Domenico, Giuseppe Ricciardi, Ernesto Gugliandolo, 2019. HYPERLINK "https://www.sciencedirect.com/science/article/pii/S0950061818328915" Compressive and flexural strength of fiber-reinforced foamed concrete: Effect of fiber content, curing conditions and dry density. Construction and Building Materials, Volume 198, 20 February 2019, Pages 479-493.

[33]Pengda Li, Lili Sui, Feng Xing, Yingwu Zhou. $2019 . \quad$ HYPERLINK "https://www.sciencedirect.com/science/article/pii/S1359836818325617" Static and cyclic response of lowstrength recycled aggregate concrete strengthened using fiber-reinforced polymer. Composites Part B: Engineering, Volume 160, 1 March 2019, Pages 37-49.

[34]C. L. Xin, Z. Z. Wang, J. M. Zhou, B. Gao. $2019 . \quad$ HYPERLINK "https://www.sciencedirect.com/science/article/pii/S0886779818307430" Shaking table tests on seismic behavior of polypropylene fiber reinforced concrete tunnellining. Tunnelling and Underground Space Technology, Volume 88, June 2019, Pages 1-15.

[35] Edward F. O’Neil, Weiguo Shen, Hamlin M. Jennings, Jeffrey J. Thomas, and Toney Cummins.2012. Development of Frangible Concrete to Reduce Blast-Related Casualties. ACI MATERIALS JOURNAL. Title no. 109-M04.

Citation: Moein Zargar, et.al. "Resistivity Comparison of Concretes Receptacle of Yam to Produce Concrete Sheets with a High Resistance”, International Journal of Constructive Research in Civil Engineering, 5(2), pp. 20-26. DOI: http://dx. doi.org/10.20431/2454-8693.0502003

Copyright: () 2019 Authors, This is an open-access article distributed under the terms of the Creative Commons Attribution License, which permits unrestricted use, distribution, and reproduction in any medium, provided the original author and source are credited. 